KANSAS JOURNAL of MEDICINE

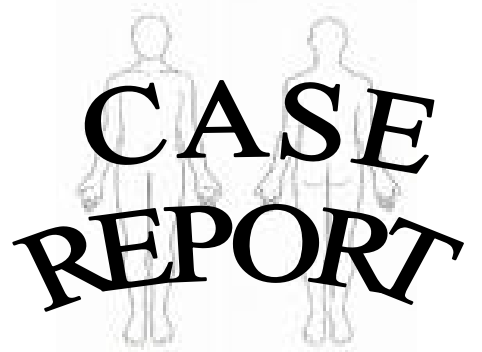

\section{Arcanobacterium Brain Abscesses, Subdural Emphyema, and Bacteremia Complicating Epstein-Barr Virus Mononucleosis}

\author{
Victoria Poplin, M.D. ${ }^{1}$, David S. McKinsey, M.D. ${ }^{2}$ \\ ${ }^{1}$ University of Kansas Medical Center, \\ Department of Internal Medicine, Kansas City, KS \\ ${ }^{2}$ Infectious Disease Associates of Kansas City, \\ Kansas City, MO
}

\section{INTRODUCTION}

Infectious mononucleosis is common among adolescents and young adults. ${ }^{1}$ Although most cases resolve spontaneously, several life-threatening manifestations have been recognized. No guidelines for management of mononucleosis have been published. However, the American Academy of Pediatrics recommends that a short course of corticosteroid therapy may be considered for certain serious complications such as impending airway obstruction, massive splenomegaly, hemolytic anemia, hemophagocytic lymphohistiocytosis, or myocarditis. ${ }^{2}$ Although some physicians prescribe prednisone for symptomatic treatment of other manifestations of mononucleosis, such as sore throat without airway obstruction, a recent Cochrane review identified no apparent benefit of steroid therapy for uncomplicated mononucleosis ${ }^{3}$; such treatment is not recommended despite its widespread use.

Sinusitis is a well-recognized complication of viral infections ,including mononucleosis. Corticosteroid therapy, even when only prescribed for brief periods, increases the risk of a variety of bacterial, viral, mycobacterial, and parasitic infections by $60 \% .{ }^{4}$ Fardet et al. reported a 5.84-fold increased relative hazard of lower respiratory tract infections among patients who received systemic steroid treatment for any reason (the prevalence of upper respiratory tract infections including sinusitis was not studied). ${ }^{5}$

Arcanobacterium haemolyticum is a slowly growing, facultative anaerobic gram-positive bacillus. ${ }^{6}$ Originally named Corynebacterium haemolyticum when recognized as a cause of exudative pharyngitis in US soldiers and natives of the South Pacific in 1946, the organism's name was changed to Arcanobacterium haemolyticum in 1982 after cell wall components and chemotaxonomic features were noted to differ from Corynebacterium spp. Humans are the primary reser- voir for A. haemolyticum, which has two biotypes, rough and smooth. The smooth biotype is a cause of pharyngitis in healthy adolescents whereas the rough biotype is associated with a variety of invasive infections which are more commonly seen in immunocompromised adults. ${ }^{6}$ The aptly-named Arcanobacterium ("secret bacterium") is difficult to cultivate with conventional culture techniques (i.e., incubation of specimens on sheep's blood agar for 24 hours). One study reported that yield was highest when horse blood agar was utilized and specimens were incubated with supplemental $5 \% \mathrm{CO}_{2}$ incubation for 48 hours. ${ }^{7}$ However, community laboratories do not typically use horse blood agar; thus the true prevalence of Arcanobacterium infections is likely higher than has been reported.

We report a case of Epstein-Barr Virus (EBV) mononucleosis treated with prednisone complicated by secondary bacterial sinusitis with intracranial extension leading to brain abscesses and subdural empyema, associated with Arcanobacterium bacteremia. To our knowledge this is the first report of EBV-associated Arcanobacterium haemolyticum brain abscess and subdural empyema.

\section{CASE REPORT}

A previously healthy 20-year-old African American male college football player developed sore throat, fatigue, and painful cervical lymphadenopathy. The diagnosis of infectious mononucleosis was established on the basis of a positive heterophile antibody test. One week later he had worsening sore throat and headache. Prednisone was prescribed for 10 days. Over the following two weeks he had recurrent fevers, chills, malaise, anorexia, and insomnia, but delayed seeking further medical attention because he was busy taking final examinations. His symptoms progressively worsened.

Three days prior to hospitalization he developed global headache, copious green rhinorrhea, recurrent rigors, and severe anorexia. He presented at a hospital emergency department where he appeared acutely ill. Posterior cervical lymph nodes were swollen and tender. No pharyngeal erythema or exudate was noted. No focal deficits were identified on neurologic examination.

His white blood cell count (WBC) was 16,300/ $\mu \mathrm{L}$ (64\% neutrophils, $24 \%$ bands, $7 \%$ monocytes, $5 \%$ lymphocytes). Total bilirubin was $5.7 \mathrm{U} / \mathrm{L}$ (direct $4.0 \mathrm{U} / \mathrm{L}$ ), AST $410 \mathrm{U} / \mathrm{L}$, ALT $290 \mathrm{U} / \mathrm{L}$, and alkaline phosphatase $331 \mathrm{U} / \mathrm{L}$. Epstein Barr virus viral capsid IgM serology was positive; viral capsid IgG serology was negative.

Computerized tomography scan of the head without contrast showed pansinusitis without intracranial masses, edema, or midline shift. Cerebrospinal fluid WBC count was $2,800 / \mu \mathrm{L}$ (46\% neutrophils, $44 \%$ lymphocytes), glucose $44 \mathrm{mg} / \mathrm{dL}$, and protein $100 \mathrm{mg} /$ dL. Gram's stain showed no organisms; culture, which was submitted prior to initiation of antibiotic therapy, was negative. Cerebrospinal fluid EBV PCR was positive (not quantified); 16s RNA was negative.

The patient was hospitalized and treated with ceftriaxone, doxycycline, and vancomycin. Doxycycline was discontinued after four days. Two of two sets of blood cultures grew Arcanobacterium haemolyticum; identification of the organism was confirmed by Matrix-assisted laser desorption/ionization (MALDI TOF) testing. Over the following four days the patient complained of worsening headache. MRI scan of the brain, with gadolinium, on hospital day five demonstrated 
multilocular fluid collections with enhancing margins in the left temporal lobe and posterior inferior left frontal lobe, consistent with abscesses, and a subdural fluid collection in the anterior and inferior left cranial fossa (Figure 1). Metronidazole was added to his treatment regimen.

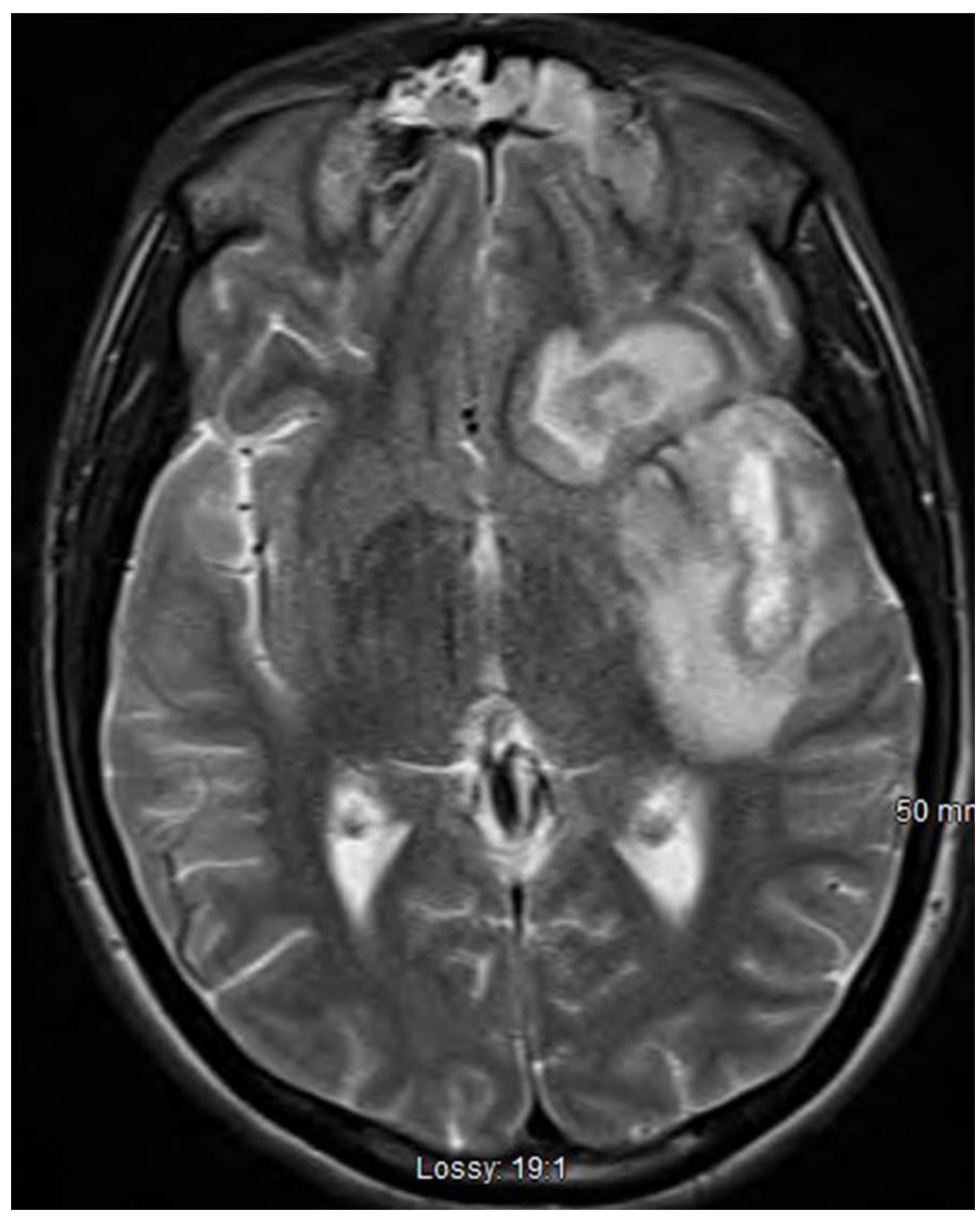

Figure 1. MRI scan of the brain, with gadolinium, demonstrated multilocular fluid collections with enhancing margins in the left temporal lobe and posterior inferior left frontal lobe, and a subdural fluid collection in the anterior and inferior left cranial fossa.

The patient underwent image-guided pterional craniotomy with evacuation of frontal and temporal brain abscesses and removal of subdural empyema. Purulent fluid was encountered. Gram's stain showed few polymorphonuclear leukocytes and rare gram positive bacilli with morphology characteristic of Arcanobacterium; culture was negative. He also underwent bilateral maxillary antrostomy, total ethmoidectomy, frontal sinusotomy, sphenoidotomy, sinus irrigation, and submucosal reduction of the inferior turbinates. Thick mucopurulent fluid was encountered. Culture was negative.

Following evacuation of the brain abscesses and subdural empyema, the patient's clinical status improved substantially. His fever and headaches abated. He received a nine-week course of intravenous ceftriaxone and metronidazole. Repeat imaging at the completion of his treatment demonstrated resolution of intracranial abscesses. His infection has not recurred during a two-year follow-up period.

\section{DISCUSSION}

We report a case of EBV mononucleosis treated with prednisone complicated by secondary bacterial sinusitis with intracranial exten-
KANSAS JOURNAL of MEDICINE EPSTEIN-BARR VIRUS MONONUCLEOSIS continued.

sion leading to brain abscesses and subdural empyema, associated with Arcanobacterium bacteremia. The dominant causative organism of the brain abscess and subdural empyema likely was Arcanobacterium: although abscess culture was negative following several days of antibiotic therapy, abscess fluid Gram's stain showed only gram positive bacilli with an appearance consistent with Arcanobacterium. We postulate that EBV infection caused disruption of upper respiratory tract epithelium, triggering secondary bacterial sinusitis with subsequent contiguous spread of infection to the brain and subdural space in the setting of transient immunosuppression precipitated by EBV and exacerbated by prednisone therapy. To our knowledge, this is the first report of EBV-associated Arcanobacterium haemolyticum brain abscess and subdural empyema.

Pharyngitis is the most commonly recognized form of $A$. haemolyticum infection. ${ }^{8}$ In half of cases a prominent erythematous rash is seen. Arcanobacterium accounts for $2 \%$ of cases of pharyngitis in 15 - 18 year old healthy males. Several other forms of Arcanobacterium infection have been reported, including sinusitis ${ }^{9}$, pneumonia ${ }^{10}$, bacteremia $^{11}$, meningitis ${ }^{12}$, and brain abscess. ${ }^{10,13-15}$ Bacteremia is rare. Two cases were identified during a 15-year period at the Karolinska Institute. ${ }^{16}$ A similar experience was reported at Ben Taub Hospital in Houston, where among 280,000 blood cultures from 2000 - 2015, only two grew Arcanobacterium. ${ }^{13}$ Skin and soft tissue infections typically are seen in older men who either are immunocompromised or have an underlying disease such as diabetes mellitus. ${ }^{10,16}$

The association of life-threatening Arcanobacterium infection with a concomitant Epstein Barr virus infection was of interest in our case. In invasive infections such as brain abscess, bacteremia, pneumonia, and Lemierre's syndrome, A. haemolyticum typically acts as a co-pathogen with other bacteria or viruses, for reasons that remain unclear. ${ }^{11,14,17}$ Monomicrobial invasive Arcanobacterium infections, in contrast, are uncommon. In a retrospective study, all six patients with Arcanobacterium bacteremia were found to have co-infection with a second bacterial species. ${ }^{18}$ The second bacterium presumably acted synergistically with $A$. haemolyticum to enhance its pathogenicity.

Although both Epstein Barr Virus mononucleosis and A. haemolyticum pharyngitis are encountered most commonly in persons between the ages of 15 - 24, concomitant infection has been recognized infrequently.,14,19-21 Three cases of $A$. haemolyticum bacteremia with primary EBV infection have been reported, one of which had secondary bacterial sinusitis and polymicrobial bacteremia. ${ }^{20}$ However, this association may be more common than has been widely recognized. A study of 13 patients with $A$. haemolyticum bacteremia detected heterophile antibody positivity in five cases. ${ }^{9}$ Secondary bacterial infections (most commonly caused by beta hemolytic streptococci) are known to be associated with EBV, likely due to either temporary immune suppression or co-pathogenicity. ${ }^{22,23}$ Thus, transient humoral and cell mediated immunosuppression induced by EBV may enhance $A$. haemolyticum's virulence.,14,21,23,24 
KANSAS JOURNAL of MEDICINE EPSTEIN-BARR VIRUS MONONUCLEOSIS continued.

\section{ACKNOWLEDGEMENT}

The authors thank Carrie Poteete, MLS (ASCP), MPH for assistance with confirmation of culture results and Kitty Serling, MLS for reviewing computerized databases for information about our topic.

\section{REFERENCES}

${ }^{1}$ Luzuriaga K, Sullivan J. Infectious mononucleosis. N Engl J Med 2010; 362(21):1993-2000. PMID: 20505178.

2 Jackson MA, Long SS, Kimbertin DW, Brady MT. (Eds.) Epstein-Barr Virus Infections (Infectious Mononucleosis). In: Red Book 2015: Report of the Committee on Infectious Diseases. 30th edition. Elk Grove Village, IL: American Academy of Pediatrics, 2015, pp 336-339. ISBN-13: 978-1-58110926-9.

3 Rezk E, Nofal YH, Hamzeh A, Aboujaib MF, AlKheder MA, Al Hammad MF. Steroids for symptom control in infectious mononucleosis. Cochrane Database Syst Rev 2015; (11): CDO04402. PMID: 26558642.

${ }^{4}$ Rostaing L, Malvezzi P. Steroid-based therapy and risk of infectious complications. PLoS Med 2016; 13(5):el002025. PMID: 27218466.

${ }_{5}^{5}$ Fardet L, Petersen I, Nazareth I. Common infections in patients prescribed systemic glucocorticoids in primary care: A population-based cohort study. PLoS Med 2016; 13(5): elO02024. PMID: 27218256.

${ }^{6}$ Carlson P, Lounatmaa K, Kongtianen S. Biotypes of Arcanobacterium haemolyticum. J Clin Microbiol 1994; 32(7):1654-1657. PMID: 7929753.

7 García-de-la-Fuente C, Campo-Esquisabel AB, Unda F, Ruiz de Alegría C, Benito N, Martínez-Martínez L. Comparison of different culture media and growth conditions for recognition of Arcanobacterium haemolyticum. Diagn Microbiol Infect Dis 2008; 61(2): 232-234. PMID: 18325709.

8 MacKenzie A, Fuite LA, Chan FTH, et al. Incidence and pathogenicity of Arcanobacterium haemolyticum during a 2-year study in Ottawa. Clin Infect Dis 1995; 21(1):177-181. PMID: 7578727.

9 Volante M, Corina L, Contucci A, Calò L, Artuso A. Arcanobacterium haemolyticum: Two case reports. Acta Otorhinolaryngol Ital 2008; 28(3):144-146. PMID: 18646577.

10 Therriault BL, Daniels LM, Carter YL, Raasch RH. Severe sepsis caused by Arcanobacterium haemolyticum: A case report and review of the literature. Ann Pharmacother 2008; 42(11):1697-1702. PMID: 18812563.

11 Stacey A, Bradlow A. Arcanobacterium haemolyticum and Mycoplasma pneumoniae co-infection. J Infect 1999; 38(1):41-42. PMID: 10090506.

${ }_{12}$ Tan TY, Ng SY, Thomas H, Chan BK. Arcanobacterium haemolyticum bacteraemia and soft tissue infections: Case report and review of the literature. J Infect 2006; 53(2):e69-74. PMID: 16316687.

${ }^{13}$ Cortés-Penfield N, Kohli A, Weatherhead J, El Sahly H. Arcanobacterium haemolyticum central nervous system abscess and bacteremia following head trauma: A case report and literature review. Infect Dis Clin Pract 2017; 25(3):e9-ell.

${ }^{14}$ Chhang WH, Ayyagari A, Sharma BS, Kak VK. Arcanobacterium haemolyticum brain abscess in a child (a case report). Indian J Pathol Microbiol 1991; 34(2):145-148. PMID: 1752643.

15 Ouriemchi W, Jeddi D, El Quessar A, Benouda A. [Arcanobacterium haemolyticum brain abscess mimicking a brain tumor]. Med Mal Infect 2011; 41(7):397-399. PMID: 21440388.

${ }^{16}$ Hedman K, Brauner A. Septicaemia caused by Arcanobacterium haemolyticum smooth type in an immunocompetent patient. J Med Microbiol 2012; 6l(Pt 9):1328-1329. PMID: 22628455.

${ }_{17}$ Lundblom K, Jung K, Kalin M. Lemierre syndrome caused by co-infection by Arcanobacterium haemolyticum and Fusobacterium necrophorum. Infection 2010; 38(5): 427-429. PMID: 20661621.

18 Skov RL, Sanden AK, Danchell VH, Robertsen K, Ejlertsen T. Systemic and deep-seated infections caused by Arcanobacterium haemolyticum. Eur J Clin Microbiol Infect Dis 1998; 17(8):578-582. PMID: 9796659.

19 Goudswaard J, Van De Merwe DW, van der Sluys P, Doom H. Corynebacterium haemolyticum septicemia in a girl with mononucleosis infectiosa. Scand J Infect Dis1988; 20(3):339-340. PMID: 3406673.

${ }^{20}$ Givner LB, McGehee D, Taber LH, Stein F, Sumaya CV. Sinusitis, orbital cellulitis and polymicrobial bacteremia in a patient with primary EpsteinBarr virus infection. Pediatr Infect Dis 1984; 3(3):254-256. PMID: 6739327. ${ }^{21}$ Bolis V, Karadedos C, Chiotis I, Chaliasos N, Tsabouri S. Atypical manifestations of Epstein-Barr virus in children: A diagnostic challenge. J Pediatr (Rio J) 2016; 92(2):113-121. PMID: 26802473.

22 Younus F, Chua A, Tortora G, Jimenez VE. Lemierre's disease caused by co-infection of Arcanobacterium haemolyticum and Fusobacterium necrophorum: A case report. J Infect 2002; 45(2):114-117. PMID: 12217717. 
23 Brouwer MC, Tunkel AR, McKhann GM 2nd, van de Beek D. Brain abscesses. N Engl J Med 2014; 371(5):447-456. PMID: 25075836.

${ }^{24}$ Altmann G, Bogokovsky B. Brain abscess due to Corynebacterium haemolyticum. Lancet 1973; 301(7799):378-379. PMID: 4121979.

25 Washington JA, Martin WJ, Spiekerman RE. Brain abscess with Corynebacterium hemolyticum: Report of a case. Am J Clin Pathol 1971; 56(2):212-215. PMID: 5567728.

26 Carlson P, Korpela J, Walder M, Nyman M. Antimicrobial susceptibilities and biotypes of Arcanobacterium haemolyticum blood isolates. Eur J Clin Microbiol Infect Dis 1999; 18(12):915-917. PMID: 10691208.

Keywords: Arcanobacterium, Epstein Barr virus infections, brain abscess, steroids, infectious mononucleosis
KANSAS JOURNAL of MEDICINE EPSTEIN-BARR VIRUS MONONUCLEOSIS continued. 